\title{
Isoconductivity method to study adhesion of yeast cells to gold electrode
}

\author{
Gabriel A. Ruiz ${ }^{1,3}$, Martín L. Zamora ${ }^{1,2}$ and Carmelo J. Felice ${ }^{1,2}$ \\ 1. Laboratorio de Medios e Interfases, Departamento de Bioingeniería, Facultad de Ciencias Exactas e Ingeniería, Universidad Nacional \\ de Tucumán, Tucumán, Argentina. \\ 2. Instituto Superior de Investigaciones Biológicas (INSIBIO), Consejo Nacional de Investigaciones Científicas y Técnicas (CONICET), \\ Argentina. \\ 3.E-mail any correspondence to: gruiz@herrera.unt.edu.ar
}

\begin{abstract}
In this paper, we used impedance spectroscopy and gold electrodes to detect the presence of yeast cells and monitor the attachment of these cells to the electrodes. We analyzed the effect of conductivity changes of the medium and the attachment on the electrode-electrolyte interface impedance. A three-electrode cell was designed to produce a uniform electric field distribution on the working electrode and to minimize the counter electrode impedance. Moreover, we used a small AC overpotential $(10 \mathrm{mV})$ to keep the system within the linear impedance limits of the electrode-electrolyte interface. This study proposes a new method to differentiate the impedance changes due to the attachment of yeast cells from those due to conductivity changes of the medium. The experiments showed that when the difference between the cell suspension and base solution conductivities is within the experimental error, the impedance changes are only due to the attachment of yeast cells to the electrodes. The experiments also showed a strong dependence (decrease) of the parallel capacity of the electrode electrolyte interface with the yeast cell concentration of suspension. We suggest that this decrease is due to an asymmetrical redistribution of surface charges on both sides of cell, which can be modeled as a biologic capacity connected in series with the double layer capacity of the interface. Our results could help to explain the rate of biofilm formation through the determination of the rate of cell adhesion.
\end{abstract}

Keywords: Electrode electrolyte interface, yeast, attachment, impedance, frequency

\section{Introduction}

The dielectric behavior of biological suspensions has been widely studied. Nonlinear dielectric spectroscopy of microbiological suspensions was firstly proposed by the group of Woodward and Kell in 1990. They reported a biological effect under an applied sinusoidal electric field of less than $5 \mathrm{Vcm}^{-1}$ [1-3]. Such a nonlinear system should generate harmonics in the current polarisation that can be measured by Fourier analysis. Based on this fact, a nonlinear spectrometer was designed to evaluate some biological samples such as Saccharomyces cerevisiae [1]. However, the spectrometer could not prevent nonlinearity due to electrode-electrolyte interface (EEI) [4-5]. Others groups also failed to eliminate the nonlinearity of the EEI, despite the use of high technology systems. [6-8]. Fortunately, in our previous study, we performed measurements with different cells and obtained relevant results with the three-electrode cell [9]. Our results indicated that the changes in the third harmonic were due to the presence of microorganisms near the EEI [9], where they were consistent with Blake-Coleman's results [10]. In all of these studies, it was not indicated whether the changes in the amplitude of the third harmonic originated in changes in the double-layer capacity or in charge transfer resistance. From an electrochemical point of view, it is not clear what is changing in the electrode-electrolyte interface.

Interestingly, it has also been shown that the attachment of microorganisms to the EEI could produce two effects, both of which reduce the double-layer capacity [11-14]. The first and more important effect is the reduction of the effective surface of the electrode, similar to a bubble curtain on the electrode [15]. The second effect is the change in the microstructure of the double layer capacity. Muñoz-Berbel did not model the double layer capacity; instead, the confusing constant phase element (CPE) was used to fit the data.

Muñoz-Berbel describes a new method based on impedance spectroscopy to detect bacterial attachment. Attachment to the electrode surface usually occurs in two stages [16]. The first stage, called reversible attachment, is a fast initial adsorption phase governed by physical forces such as electrostatic and van der Waals forces. It is probable that the bacteria require the use of appendages called flagella to overcome these physical forces [17-19]. The second stage, called irreversible attachment, is a slow phase in which the bacteria adhere tightly to the electrode surface via pili, binding proteins and polysaccharides for the conditioning layer [20]. Measurements of the magnitude of CPE versus time for the following cell suspensions are presented: total samples containing both cells and released substances, samples only containing released substances, samples containing only cells and samples of secreted substance after filtration. In this work, the changes in the CPE magnitude were due to, not only yeast attachment but also to changes in conductivity. When the results of samples after filtration and total sample without filtration were compared, between $50 \%$ and $70 \%$ of changes in CPE were due to the suspending medium [21].

The adherence of eukaryotic cells to planar gold film electrodes has also been studied by other groups [22-27]. Nor do these publications mention having taken into 
account the effect of changes in conductivity of the medium on the impedance measurements.

The present study had two objectives. The first one was to propose a new method to detect and monitor the attachment of yeast cells to the electrodes but avoiding changes in the conductivity of the suspensions. The second one was the electrochemical characterization of the yeast attachment using the proposed method. We have shown that the impedance measurements of EEI are sensitive to both attachment processes and changes in the conductivity of the suspensions. The proposed method is based on keeping constant the medium conductivity to avoid impedance changes due to suspension conductivity changes. To confirm that the changes in impedance measurements were only due to yeast attachment, we have done three things: the first was to show experimentally that the lower the difference between the supernatant and base solution conductivities, the lower the change in impedance. And so in the limit, when the supernatant and base solution conductivities are equal within the experimental error, impedance will not change. The second was to show experimentally that when the cell suspension and base solution conductivities are equal within the experimental error, it was observed an important impedance change. Finally the last one thing we did was to take SEM images of the naked electrode and after the measurements in which supernatant and cell suspension was added. Finally, a physical model explaining the observed behavior was proposed.

\section{Materials and methods}

\subsection{Electrochemical cell}

A three-electrode cell is composed of a working electrode (WE) and a $\mathrm{Ag} / \mathrm{AgCl}$ reference electrode (Re1). An AISI 304 stainless steel concave counter-electrode (CE) $85 \mathrm{~mm}$ in diameter was also used (Fig. 1). The WE was a solid cylinder (1.5 cm long) with only $1 \mathrm{~cm}^{2}$ of its transversal section exposed and coated with gold; the rest was insulated with Grilon. The CE was made with a larger area than the working electrode to minimize its impedance.

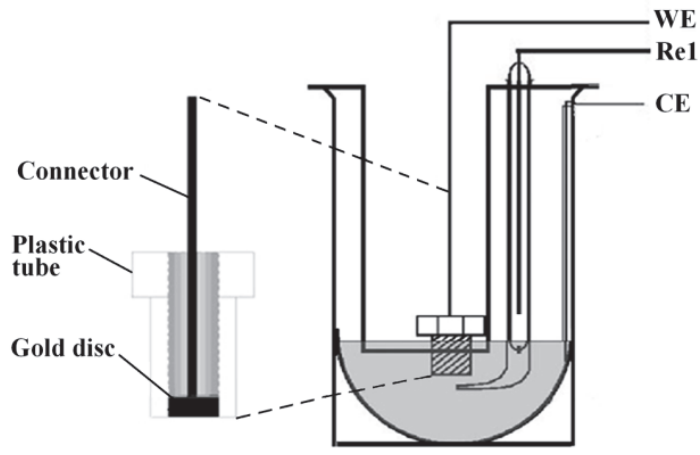

Fig.1: Three-electrode cell. WE: working electrode, Re1: reference electrode, $\mathrm{CE}$ : counter-electrode.

\subsection{Measurement System}

Electrochemical measurements were performed which a Solartron 12508W impedance analyzer composed of a Solartron 1287 Electrochemical Analyzer and a Solartron 1250 Frequency Response Analyzer, commanded by the software provided by the manufacturer (ZPlot ${ }^{\circledR}$, Scribner Associates Incorporated).

\subsection{Polishing electrodes}

The electrodes were polished in gradual steps with different degrees of roughness, according to the diagram indicated in Table 1. The size of the grain matches the European standards FEPA standard 43-GB-1984 (R1993).

Table 1: Steps for polishing electrodes.

\begin{tabular}{llc}
\hline Step & Abrasive & Final roughness $/ \mu \mathrm{m}$ \\
\hline 1 & Diamond pasta Praxis ${ }^{\circledR}$ & 6 \\
2 & Diamond pasta Praxis ${ }^{\circledR}$ & 3 \\
3 & Alumina powder & 1 \\
\hline
\end{tabular}

\subsection{Microbiological preparation}

Different media were used in the assay:

1. Base Solution (BS): $20 \mathrm{mM}$ of $\mathrm{KH} 2 \mathrm{PO} 4,30 \mathrm{mM}$ of $\mathrm{KCl}, 1 \mathrm{mM}$ of $\mathrm{MgCl}$, to $\mathrm{pH} 6.5$, where $\mathrm{mM}=$ $\mathrm{mmol} / \mathrm{L}$.

2. Yeast cell Suspension (YCS).

The YCS $\left(10^{9} \mathrm{CFU} / \mathrm{ml}\right)$ was obtained by dissolving $9.33 \mathrm{~g}$ of dry yeast in $100 \mathrm{ml}$ of BS and stirring for $5 \mathrm{~min}$ with a magnetic stirrer. Then, $65 \mathrm{ml}$ this solution was centrifuged for $10 \mathrm{~min}$ at $5000 \mathrm{rpm}$. The pellet was resuspended in 65 $\mathrm{ml}$ of BS and magnetically stirred. This process was repeated five times to ensure the complete removal of the biological material ions that may contain commercial yeast (Levex ${ }^{\circledR}$ ) and to ensure that the conductivity of final suspension of washed yeasts (YW) had the same conductivity as BS $(5.47 \pm 0.04) \mathrm{mS} / \mathrm{cm}$. The YCS was then serially diluted thrice down to $10^{7} \mathrm{CFU} / \mathrm{ml}$ in decade steps. The centrifuge and resuspend process was repeated 4 and 2 times for samples of $10^{8}$ and $10^{7} \mathrm{CFU} / \mathrm{ml}$ respectively (Fig. 2 ). The conductivities were measured with an OAKTON ${ }^{\circledR}$ portable conductivity meter. All supernatants obtained after centrifugation were reserved. The concentrations were measured in colony forming units per milliliter (CFU ml-1) by using the plate count method. Before measurements, biological samples were stored in the fridge at $4{ }^{\circ} \mathrm{C}$ to slow growth. All of the manipulations were performed under sterile conditions. 


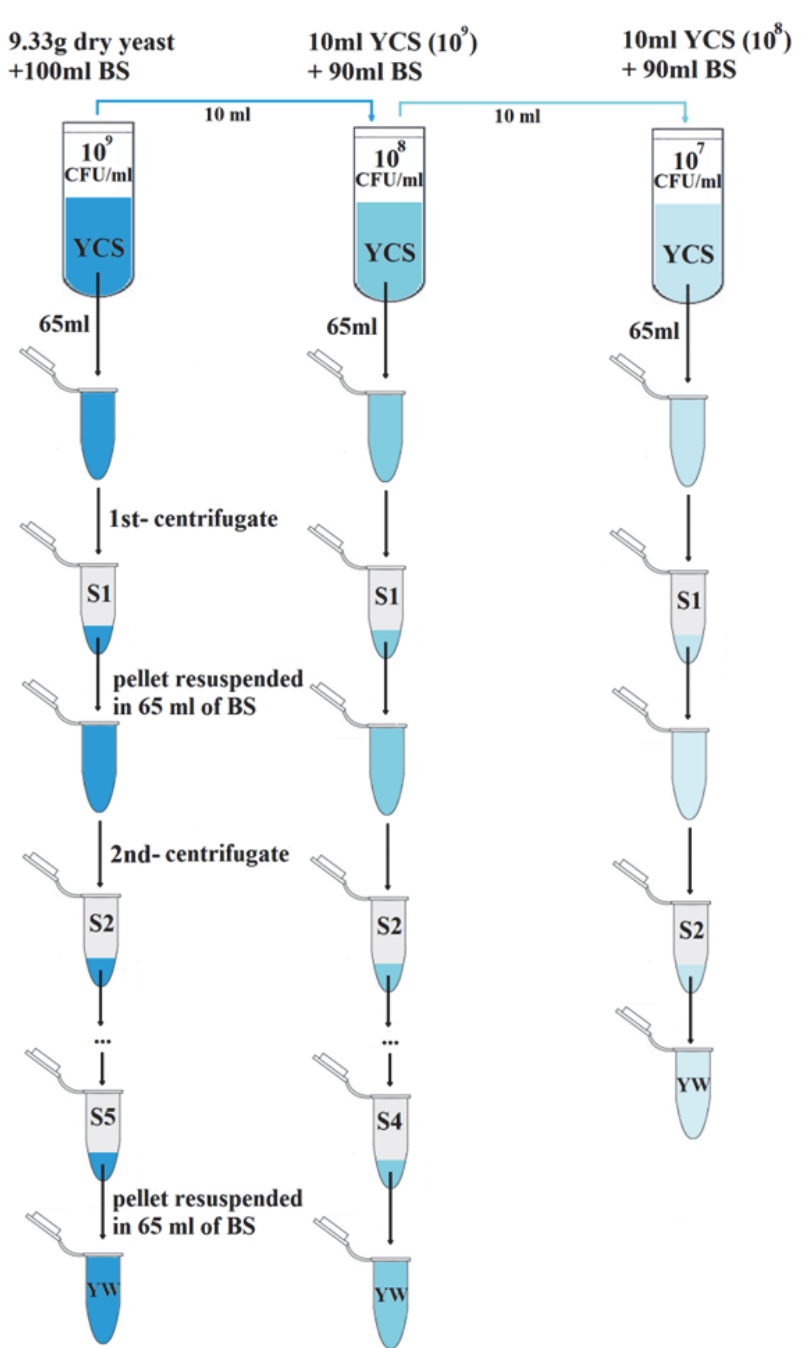

Fig.2: Serial dilution of yeast cell suspension (YCS) and steps to get final suspension of washed yeasts $(\mathrm{YW}) . \mathrm{Sn}=$ supernatants obtained after nth-centrifugation.

\subsection{Measurement protocol}

$\mathrm{AC}$ overpotentials $(10 \mathrm{mV}$ vs. $\mathrm{Ag} / \mathrm{AgCl})$ with frequencies within the interval of 1 to $65,000 \mathrm{~Hz}$ were applied with the Solartron system. The sampling frequency was such that the measurement points were equally spaced on a logarithmic scale, with 10 points per decade. The integration time of the measurements was 10 cycles. In every case, the potential was stabilized in open circuit until the open circuit potential shift was lower than $0.05 \mathrm{mV} \mathrm{s}^{-1}$. The temperature was stabilized at $23^{\circ} \mathrm{C}$. The experiments were fully controlled by PC. The measurement protocol was as follows. (1) A frequency sweep was performed using an electrolyte solution $65 \mathrm{ml}$ of BS. (2) The temporal evolution of $R_{p}$ and $C_{p}$ was obtained from measurement of the temporal evolution of the complex impedance $Z^{*}(t)=Z^{\prime}(t)+\mathrm{j} Z^{\prime \prime}(t)$ under the application of an overpotential of $10 \mathrm{mV}$ (vs.
$\mathrm{Ag} / \mathrm{AgCl})$ at $20 \mathrm{~Hz}^{1} ; \mathrm{j}=\sqrt{-1}, Z^{\prime}(t)$ and $Z^{\prime \prime}(t)$ are the real and imaginary parts of the complex impedance $Z^{*}(t)$ at time t. $C_{p}$ and $R_{p}$ are components of the parallel circuit model. (3) During these measurement, $5 \mathrm{ml}$ of supernatant or YW was added. (4) After reaching a new steady state, a second frequency sweep was performed.

The assay described above was repeated 5 times for the three concentrations with all supernatants $S_{n}$ (were $n$ indicates that the supernatant $S$ was obtained after the nthcentrifugation) and YW. In each trial, frequency sweeps were performed before and after adding the supernatant or YW. Circular fittings in the complex plane were performed.

From these fittings, values of $R_{c t}$ before $\left(R_{c t b}\right)$ and after $\left(R_{c t a}\right)$ addition of different media were obtained. Paired samples t-tests were performed on these results.

\subsection{Scanning electron microscopy (SEM)}

After experiments with supernatant S1 and YW that came from a concentration of $10^{9} \mathrm{CFU} / \mathrm{ml}$, the electrodes were taken out from the medium and tested under a Zeiss Supra 55 VP scanning electron microscope provided by the Centro Integral de Microscopía Electrónica (CIMEUniversidad Nacional de Tucumán-CONICET). Also a naked electrode was directly tested under SEM without gold coating.

\section{Results}

The Argand diagram in Fig. 3 (complex plane) shows, as an example, the frequency sweeps with BS, YW $\left(10^{9} \mathrm{CFU} / \mathrm{ml}\right)$ and the circular fitting. The horizontal and vertical axes show $Z^{\prime}(\omega)$ and $-Z^{\prime \prime}(\omega)$, where $Z^{\prime}(\omega)$ and $Z^{\prime \prime}(\omega)$ are the real and imaginary parts of the complex impedance, respectively; $Z^{*}(\omega)=Z^{\prime}(\omega)+\mathrm{j} Z^{\prime \prime}(\omega) . \quad Z(\omega)$ at high frequencies tends to $R_{m}$ (78 $\Omega$ ), representing the small electrolytic resistance between the reference electrode and the working electrode. This may be appreciated in the left inset of Fig. 3.

Fig. 3 shows that the loci for YW and BS coincide, but there is a shift of the points corresponding to the same frequency. This behavior is observed for the three concentrations and in all situations. In this case, the point corresponding to the impedance at a frequency of $1 \mathrm{~Hz}$ is indicated with black and red arrows. This may be appreciated in the right inset of Fig. 3.

Fitted values of $R_{c t}$, before $\left(R_{c t b}\right)$ and after $\left(R_{c t a}\right)$ addition of different media and the statistical analysis performed, are shown in Table 2.

\footnotetext{
${ }^{1}$ The selecting of the frequency of $20 \mathrm{~Hz}$ was widely discussed by MuñozBerbel in [21]
} 


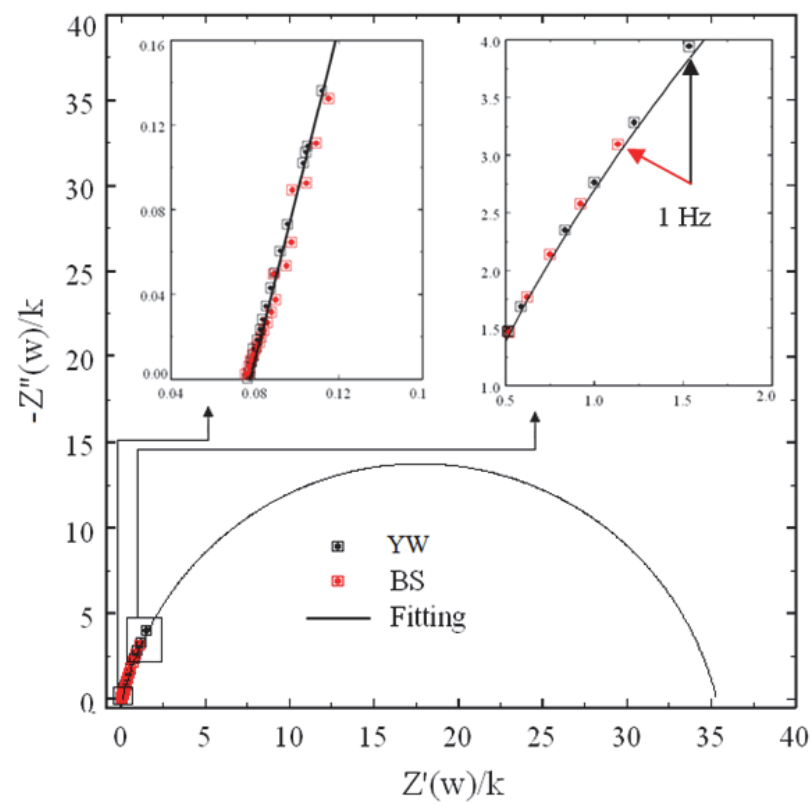

Fig.3: Argand diagram of the EEI for gold electrodes polished at $1 \mu \mathrm{m} . \mathrm{Z}^{\prime}$ and $\mathrm{Z}^{\prime \prime}$ are the real and imaginary parts of the impedance. AC overpotential $=10 \mathrm{mV}, \mathrm{DC}$ overpotential $=0 \mathrm{~V}$. Error bars for the two axes are symmetric and are represented by a box.

Table 2: Fitted values of Rct before and after addition of different media and paired samples tests.

\begin{tabular}{|c|c|c|c|c|c|c|c|}
\hline \multirow{2}{*}{$\begin{array}{l}\mathrm{CFU} \\
/ \mathrm{ml}\end{array}$} & \multirow{2}{*}{ Media } & \multirow{2}{*}{$\begin{array}{c}\mathrm{Rctb}^{2} \\
/ \mathrm{k} \Omega\end{array}$} & \multirow{2}{*}{$\begin{array}{l}\text { Rcta } \\
/ \mathrm{k} \Omega\end{array}$} & \multicolumn{2}{|c|}{$\Delta \mathrm{Rct} / \mathrm{k} \Omega$} & \multirow{2}{*}{$\mathrm{t}$} & \multirow{2}{*}{$\begin{array}{c}\text { Sig. } \\
\text { 2-tailed }\end{array}$} \\
\hline & & & & Mean & STDV & & \\
\hline \multirow{6}{*}{$10^{9}$} & S1 & 40.95 & 40.34 & .61 & .96 & 1.10 & .39 \\
\hline & S2 & 39.88 & 40.68 & -.80 & .44 & -3.15 & .09 \\
\hline & S3 & 40.05 & 40.48 & -.42 & 1.44 & -.51 & .66 \\
\hline & S4 & 40.26 & 40.37 & -.12 & .95 & -.22 & .85 \\
\hline & S5 & 40.96 & 40.75 & .21 & .24 & 1.51 & .27 \\
\hline & YW & 40.22 & 40.94 & -.72 & 1.12 & -1.11 & .38 \\
\hline \multirow{5}{*}{$10^{8}$} & S1 & 40,44 & 40,53 & -.09 & 1,26 & -.12 & .92 \\
\hline & S2 & 41.07 & 40.40 & .67 & 1.00 & 1.16 & .37 \\
\hline & S3 & 40.93 & 40.75 & .18 & 1.03 & .30 & .80 \\
\hline & S4 & 40.44 & 39.98 & .46 & .55 & 1.46 & .28 \\
\hline & YW & 40.17 & 40.36 & -.34 & 1.10 & -.53 & .65 \\
\hline \multirow{3}{*}{$10^{7}$} & S1 & 40.65 & 40.48 & .17 & 1.07 & .27 & .81 \\
\hline & S2 & 40.17 & 41.00 & -.82 & .28 & -5.07 & .08 \\
\hline & YW & 40.17 & 40.36 & -.19 & .20 & -1.64 & .24 \\
\hline
\end{tabular}

${ }^{2}$ The measurement error of Rct is $0.06 \mathrm{k} \Omega$. Sn= supernatants obtained after nth-centrifugation. $\Delta$ Rct=Rctb-Rcta.

The statistical analysis was performed with SPSS software v.17.

Fig. 4 shows the temporal evolution of $C_{p} \%$ for different media and concentrations. $C_{p}$ values were obtained from the complex impedance using the equation (1).

$$
\mathrm{C}_{\mathrm{p}}=-\frac{\mathrm{Z}^{\prime \prime}}{2 \pi f\left(\mathrm{Z}^{\prime 2}+\mathrm{Z}^{\prime \prime 2}\right)}
$$

Red arrows indicate the time in which the frequency sweeps like those shown in Fig. 3 were performed. In the first 10 min of measurement, the electrolytic solution was BS. The black arrow indicates when supernatant or YW was added. The error bars are not shown in Fig. 4 in order to clarify this figure. However were added in legends.

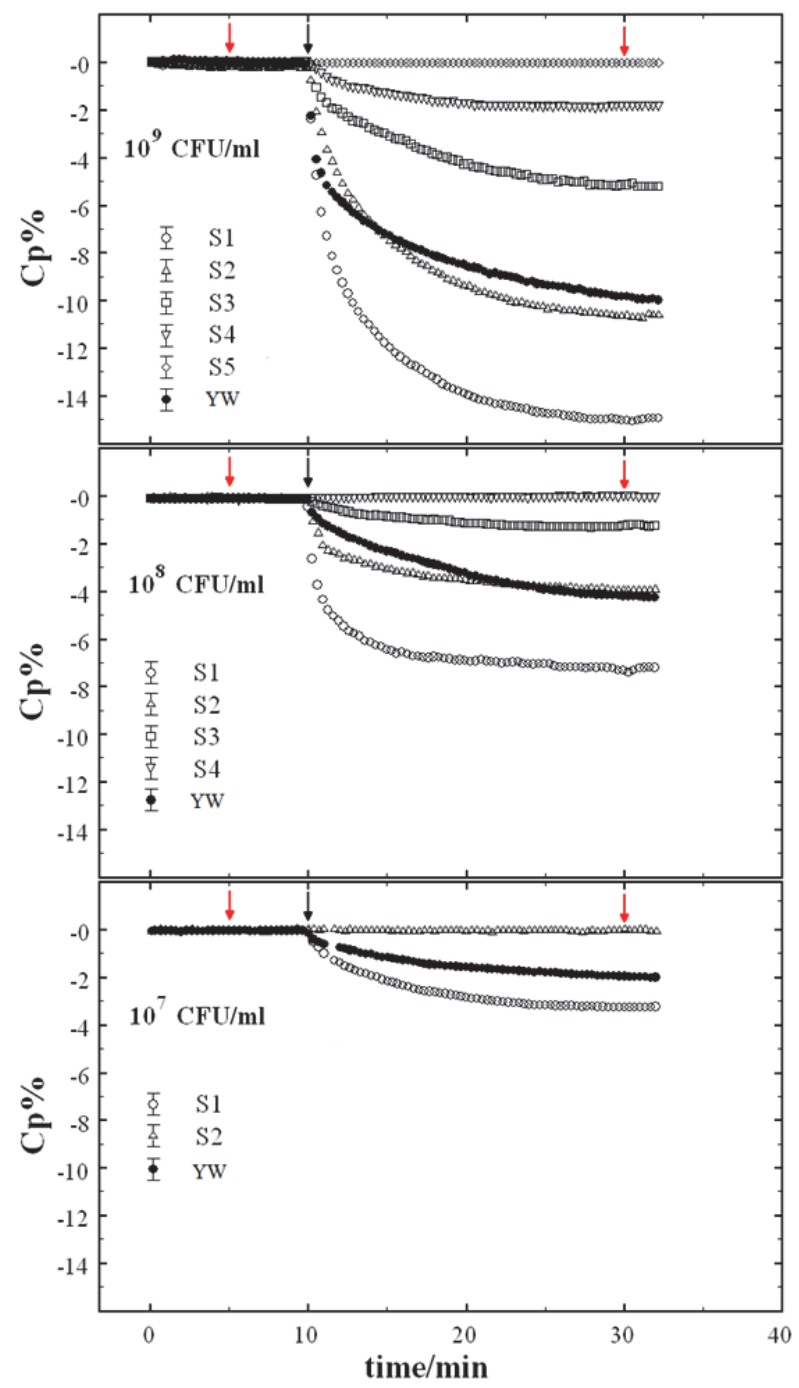

Fig.4: Temporal evolution of $C_{p} \%$ for $10^{9}, 10^{8}$ and $10^{7} \mathrm{CFU} / \mathrm{ml}$. Red arrows indicate the time in which the frequency sweeps were performed. The black arrow indicates the time at which the aggregates of supernatant or $\mathrm{YW}$ were made. Overpotential applied: $10 \mathrm{mV}$ at $20 \mathrm{~Hz}$.

Table 3: Measured conductivities and maximum values of $C_{p} \%$ observed for media used.

\begin{tabular}{cccc}
\hline CFU/ml & Media & $\sigma /\left(\mathrm{mS} \mathrm{cm}^{-1}\right)$ & $\mathrm{Cp} \%$ \\
\hline \multirow{4}{*}{$10^{9}$} & $\mathrm{~S} 1$ & $7.72 \pm 0.04$ & $-15.0 \pm 0.2$ \\
& $\mathrm{~S} 2$ & $6.76 \pm 0.04$ & $-10.6 \pm 0.2$ \\
& $\mathrm{~S} 3$ & $5.77 \pm 0.04$ & $-5.2 \pm 0.2$ \\
& $\mathrm{~S} 4$ & $5.56 \pm 0.04$ & $-1.8 \pm 0.2$ \\
& $\mathrm{~S} 5$ & $5.49 \pm 0.04$ & $0.0 \pm 0.2$ \\
& $\mathrm{YW}$ & $5.47 \pm 0.04$ & $-10.0 \pm 0.2$ \\
\hline \multirow{4}{*}{$10^{8}$} & $\mathrm{~S} 1$ & $6,08 \pm 0.04$ & $-7,3 \pm 0.2$ \\
& $\mathrm{~S} 2$ & $5.66 \pm 0.04$ & $-3.9 \pm 0.2$ \\
& $\mathrm{~S} 3$ & $5.53 \pm 0.04$ & $-1.2 \pm 0.2$ \\
& $\mathrm{~S} 4$ & $5.48 \pm 0.04$ & $0.0 \pm 0.2$ \\
$10^{7}$ & $\mathrm{YW}$ & $5.47 \pm 0.04$ & $-4.2 \pm 0.2$ \\
\hline & $\mathrm{S} 1$ & $5.62 \pm 0.04$ & $-3.3 \pm 0.2$ \\
& $\mathrm{~S} 2$ & $5.47 \pm 0.04$ & $0.1 \pm 0.2$ \\
& $\mathrm{YW}$ & $5.47 \pm 0.04$ & $-2.0 \pm 0.2$ \\
\hline
\end{tabular}

$\sigma=$ conductivity 
Table 3 shows the measured conductivities of media used and its impedance changes expressed as maximum $C_{p} \%\left(C_{p}\right.$ values for 5 and $30 \mathrm{~min}$ in Fig. 4).

Fig. 5 and 6 were obtained from data of Table 3.

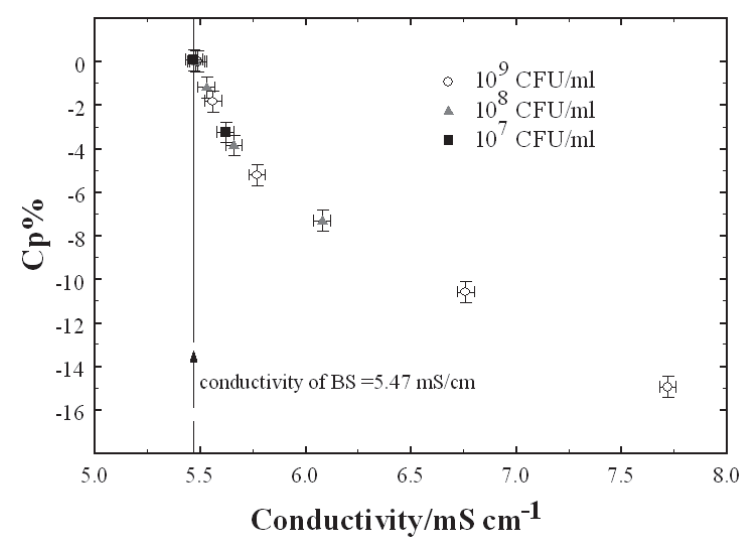

Fig.5: Dependence of $C_{p} \%$ with the supernatant conductivity.

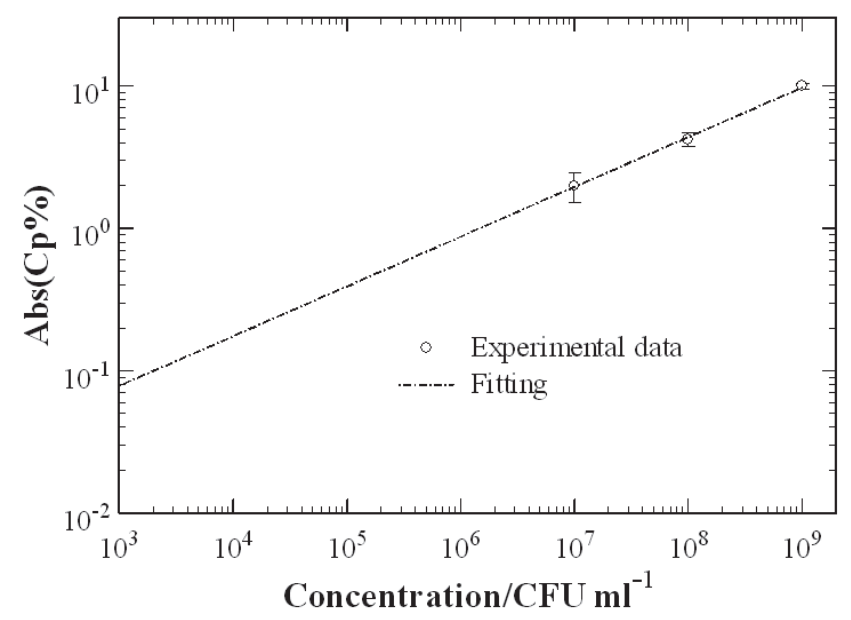

Fig.6: Dependence of $C_{p} \%$ with the yeast cells concentration.

\section{Discussion and Conclusions}

First, Fig. 3 shows that, while the loci for BS and YW coincide, there is a shift of the points corresponding to the same frequency. This shift occurs when there is a variation of the $C_{d l}$ values but not $R_{c t}$ values.

If the EEI is modeled electrically with a simple circuit consisting of an $R_{m}$ in series with the parallel combination of $R_{c t}$ and $C_{d l}$, the locus in the complex plane and the frequency dependencies of the real and imaginary parts are given by equations (2), (3) and (4), respectively:

$$
\begin{gathered}
\left(Z^{\prime}-R_{m}-\frac{R_{c t}}{2}\right)^{2}+Z^{\prime \prime 2}=\left(\frac{R_{c t}}{2}\right)^{2} \\
Z^{\prime}(\omega)=R_{m}+\frac{R_{c t}}{1+\left(\omega \cdot R_{c t} \cdot C_{d l}\right)^{2}} \\
Z^{\prime \prime}(\omega)=-\frac{\omega \cdot R_{c t}^{2} \cdot C_{d l}}{1+\left(\omega \cdot R_{c t} \cdot C_{d l}\right)^{2}}
\end{gathered}
$$

Equation (2) reflects the characteristic curve of the parallel circuit RC, which was obtained eliminating $\omega$ from Equations (3) and (4). From equation (2), we can see that the locus in the complex plane only depends on the $R_{c t}$ and $R_{m}$ values but not $C_{d l}$. This result would explain the fact that there are no statistically significant variations in the $R_{c t}$ measurements.

The statistical design was carried out to ensure that systematic and random differences between experimental units (electrodes) do not interfere with the comparison between means. T-tests for related samples were performed.

Table 2 shows that, on average, there is not a statistically significant difference for $\Delta R=R_{c t b}-R_{c t a}$ (last column).

Moreover, from equations (3) and (4), it can be seen that if $C_{d l}$ decreases, equal frequency points on the circle move to the right (that is, to higher $Z^{\prime}$ values). This result is shown in Fig. 3, where it can be seen that the black full circle corresponding to $1 \mathrm{~Hz}$ is displaced to the right in relation to the red full circle.

The effect over the impedance due to add supernatant or YW, is presented in Fig. 4. This figure shows that adding either supernatant or YW generated change in $C_{p} \%$, but for different reasons. Impedance changes observed when supernatants $\left(S_{n}\right)$ were added, were due to the different conductivity of these with respect to BS (Figure 5). These changes depend obviously on the supernatant added (S1, $\mathrm{S} 2$, etc.) and on the concentration of the YCS they come from. That is, if you add the S1 supernatant from an YCS of $10^{9} \mathrm{CFU} / \mathrm{ml}$, will not produce the same change in $C_{p} \%$ that if S1 from an YCS of $10^{8}$ or $10^{7} \mathrm{CFU} / \mathrm{ml}$ were added.

From Fig. 5, it was observed that the larger the difference between the supernatant and BS conductivities, the greater the change in $C_{p} \%$.

On the other hand, when it was added YW with the same conductivity than $\mathrm{BS}$, the change experienced by $C_{p} \%$ was due exclusively to the presence of yeast cells and not to the changes of conductivity. These facts are very important because they show that to quantify the presence of yeast cells, the effect of the difference between the supernatant and BS conductivities, must be eliminated first. This means that YCS must be washed until conductivities of YW and BS are equal within the experimental error. Moreover, if the effect of the different conductivity of the supernatant is not removed, changes in $C_{p} \%$ will be due to these two effects together and therefore the measurements will be unreliable.

The Fig. 6 shows the strong dependence of $C_{p} \%$ with the cell suspension concentration, previously washed, so that the YW and BS conductivities coincide within the experimental error. To confirm that this the changes in impedance measurements were only due to yeasts attachment, SEM images of the electrode surface have been taken in three different situations: naked electrode (Fig. 7a), after a measurement in which supernatant S1 (which comes from to concentration of $10^{9} \mathrm{CFU} / \mathrm{ml}$ ) was added (Fig. $7 \mathrm{~b}$ ) and after a measurement in which YW (also of $10^{9} \mathrm{CFU} / \mathrm{ml}$ ) was added (Fig. 7c). The first two images were taken at a 
magnification of $1000 \mathrm{x}$, while the third and its inset were taken at 150x and 2000x respectively. Note in Figure $7 \mathrm{~b}$ that no yeast cells attached to gold electrode were observed.

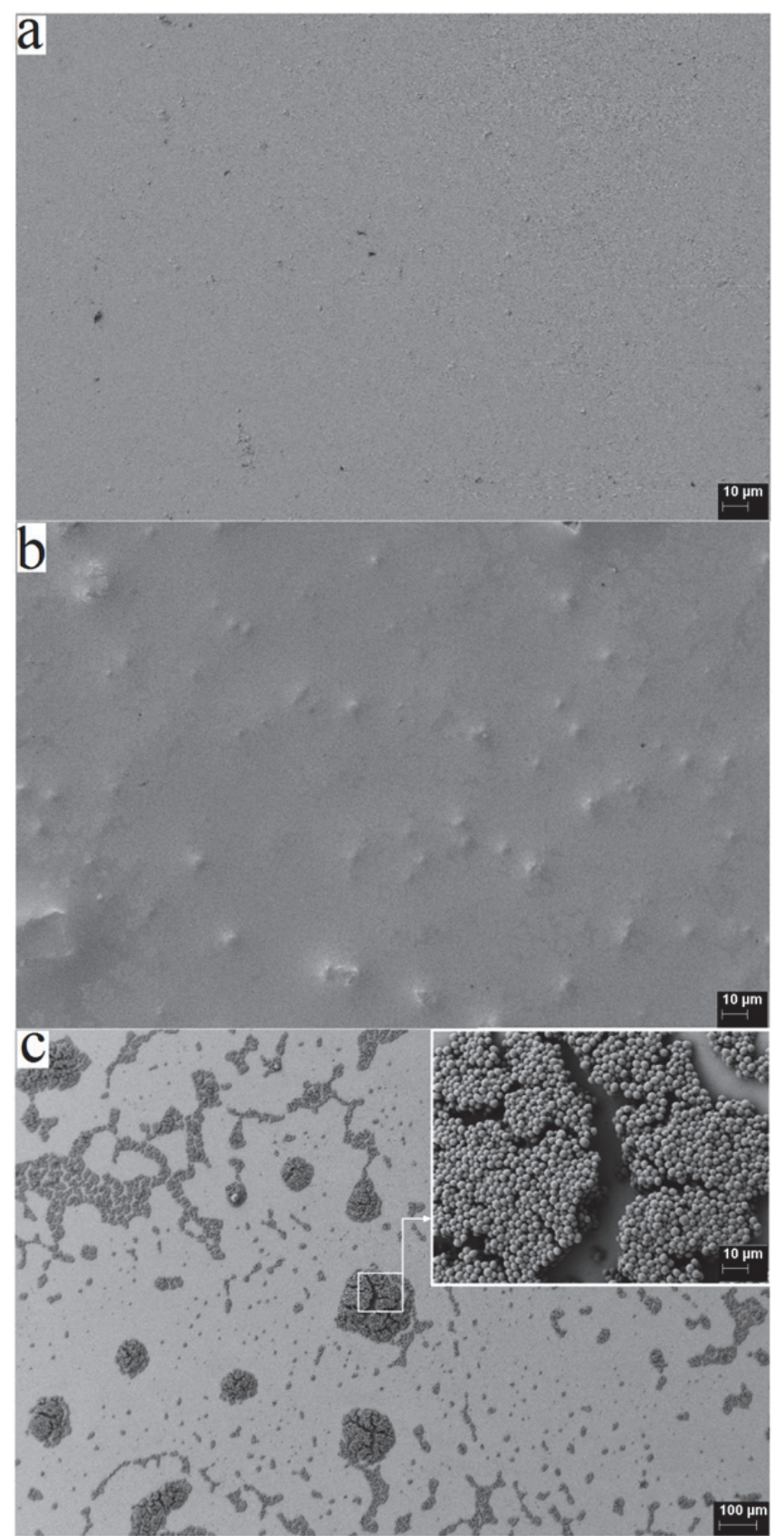

Fig.7: Images of the electrode surface in three different situations: (a) naked electrode, (b) after a measurement in which supernatant S1 was added and (c) after a measurement in which YW was added.

From a dielectric perspective, the simplest representation of a yeast cell is a sphere surrounded by a membrane and covered by a cell wall. The interior of the cell has a net negative charge, which is necessary to establish a membrane potential. The cell wall is essentially a layer of polysaccharides, proteins, lipids and inorganic phosphate.

The yeast cell surface charge originates from the presence of carboxyl, phosphate and amino groups in either dissociated or protonated form, and the surface charge consequently depends upon the $\mathrm{pH}$ [28] and/or ionic concentration of the suspending medium [29]. Poortinga et al [28] suggested that, at physiological $\mathrm{pH}$ values (i.e., between $\mathrm{pH} 5$ and 7), bacterial cells are generally negatively charged due to the excess of carboxyl and phosphate groups over amino groups.

It is known that, from an electric point of view, the cell is surrounded by a thin layer of high electrical conductivity. Most ions in this layer have the opposite charge in relation to the charge of the cell [30].

Let us consider that the net surface charge of a yeast cell is negative, while the net charge of the ions from the solution and close to the surface of the yeast cell is positive.

When the cell is near the outer Helmholtz plane (OHP), its counterion atmosphere is asymmetrically redistributed on both sides of the cell due to the presence of EEI.

The electric charges in the liquid phase (OHP and diffuse layer) are closer to the yeast cells than the electric charges in the solid phase (metallic electrode); therefore, the electric field acting on the yeast cells cannot be null.

This electric field on the yeast cell could produce a redistribution of its counterion atmosphere. As a result of this process, the cell is polarized, even in the absence of an external overpotential applied to the system. The asymmetric charge distribution can be modeled as a net capacitor $C_{b}$ in series with $C_{d l}$, as shown in Fig. 8.

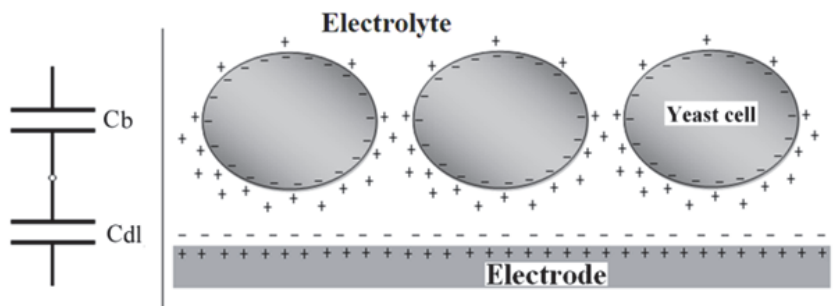

Fig.8: Explanatory model of the decrease in Cdl due to the attachment of yeast.

This model explains the behavior showed in Fig. 6. That is, the larger the yeast cell concentration, the greater the $C_{b}$ and greater the $C_{p} \%$ change, in absolute value.

The fitting shown in this Fig. is given by equation (5) which has a correlation coefficient of 0.9997 .

$$
\log _{10}\left[\operatorname{Abs}\left(C_{p} \%\right)\right]=-5.231+0.363 \log _{10}[C]
$$

where $C$ is the concentration.

When the external overpotential is applied to the EEI, an additional phenomenon occurs: (1) the potential on the EEI is modulated according to the external potential. (2) Consequently, a modulation of the asymmetric charge distribution is induced. (3) When performing a frequency sweep, the alpha relaxation phenomenon [31] could be distorted because the cells start from a previous DC polarization.

Finally, an important and novel aspect of this work is that the effect of the attachment of yeast cells on the electrode-electrolyte interface impedance was quantified 
instead of the joint effect of attachment and changes in the conductivity of the medium, as published by other authors (Muñoz-Berbel, Treo, Blake-Coleman). Consequently, this work provides the basis for future clinical and industrial applications such as the quantification of microorganism concentrations through their attachment or study of the rate of biofilm formation by impedance spectroscopy.

\section{Acknowledgements}

This work was supported by grants from the Agencia Nacional de Promoción Científica y Tecnológica, the Consejo Nacional de Investigaciones Científicas y Técnicas (CONICET), the Consejo de Investigaciones de la Universidad Nacional de Tucumán (CIUNT), and Institutional funds from INSIBIO (Instituto Superior de Investigaciones Biológicas).

The authors would like to thank Lic. Micaela García for her help in the language editing of this paper.

\section{References}

1. Woodward AM, Kell DB. On the nonlinear dielectric properties of biological Systems: Saccharomyces cerevisiae. Bioelectroch. Bioener. 1990; 24: 83-100. http://dx.doi.org/10.1016/0302-4598(90)85013-8

2. Woodward AM, Kell DB. Confirmation by using mutant strains that the membrane-bound H+-ATPase is the major source of non-linear dielectricity in Saccharomyces cerevisiae. FEMS Microbiol. Lett. 1991; 84: 91-95. http://dx.doi.org/10.1111/j.1574-6968.1991.tb04575.x

3. Woodward AM, Kell DB. Dual-frequency excitation: a novel method for probing the nonlinear dielectric properties of biological systems, and its application to suspensions of S. cerevisiae. J. Electroanal. Chem. 1991; 320: 395-413. http://dx.doi.org/10.1016/0022-0728(91)85655-9

4. Ruiz GA, Felice CJ, Valentinuzzi ME.Non-linear response of electrode-electrolyte interface at high current density. Chaos Sol. Fract. 2005; 25: 649-654. http://dx.doi.org/10.1016/j.chaos.2004.11.029

5. Ruiz GA, Felice CJ. Non-linear response of an electrodeelectrolyte interface impedance with the frequency. Chaos Sol. Fract. 2007; 31: 327-335. http://dx.doi.org/10.1016/j.chaos.2005.09.064

6. Nawarathna D, Claycomb JR, Miller J, Benedik MJ. Nonlinear dielectric spectroscopy of live cells using superconducting quantum interference devices. App. Phys. Lett. 2004; 86: 23902-23903. http://dx.doi.org/10.1063/1.1844036

7. Nawarathna D, Miller J, Claycomb JR, Cardenas G, Warmflash D. Harmonic response of cellular membrane pumps to low frequency electric fields. Phys. Rev. Lett. 2005; 95: 158103-158104. http://dx.doi.org/10.1103/PhysRevLett.95.158103

8. Nawarathna D, Miller J, Claycomb JR, Cardenas G, Gardner J, Warmflash D, Miller J. Harmonic generation by yeast cells in response to low-frequency electric fields. Phys. Rev. E.
2006; 73: 51914-51916.

http://dx.doi.org/10.1103/PhysRevE.73.051914

9. Treo E, Felice CJ. Non-linear dielectric spectroscopy of microbiological suspensions. Biomed. Eng. Online. 2005; 8: 19. http://dx.doi.org/10.1186/1475-925X-8-19

10. Blake-Coleman BC, Hutchings MJ, Silley P. Harmonic 'signatures' of microorganisms. Biosens. Bioelectron. 1994; 9: 231-242. http://dx.doi.org/10.1016/0956-5663(94)80126-6

11. Mu-oz-Berbel X, Vigués N, Mas J, Toby A, Jenkins A, Mu-oz FJ.Impedimetric characterization of the changes produced in the electrode-solution interface by bacterial attachment. Electrochem. Commun. 2007; 9: 2654-2660. http://dx.doi.org/10.1016/j.elecom.2007.08.011

12. Mu-oz-Berbel X, Vigués N, Jenkins A, Mas J, Mu-oz FJ. Impedimetric approach for quantifying low bacteria concentrations based on the changes produced in the electrode-solution interface during the pre-attachment stage. Biosens. Bioelectron. 2008; 23: 1540-1546. http://dx.doi.org/10.1016/j.bios.2008.01.007

13. Mu-oz-Berbel X, García-Aljaro C, Mu-oz FJ.Impedimetric approach for monitoring the formation of biofilms on metallic surfaces and the subsequent application to the detection of bacteriophages. Electrochim. Acta. 2008; 53: 5739-5744. http://dx.doi.org/10.1016/j.electacta.2008.03.050

14. Mu-oz-Berbel X, Vigués N, Mas J, Mu-oz FJ, Cortina-Puig $\mathrm{M}$. Resolution of binary mixtures of microorganisms using electrochemical impedance spectroscopy and artificial neural networks. Biosens. Bioelectron. 2008; 24: 958-962. http://dx.doi.org/10.1016/j.bios.2008.07.050

15. Vogt $H$. The incremental Ohmic resistance caused by bubbles adhering to an electrode. J. Appl. Electrochem. 1983; 13: 8788. http://dx.doi.org/10.1007/BF00615891

16. Palmer J, Flint S, Brooks J. Bacterial cell attachment, the beginning of a biofilm. J. Ind. Microbiol. Biotechnol. 2007; 34: 577-588. http://dx.doi.org/10.1007/s10295-007-0234-4

17. Carpentier B, Cerf O. Biofilms and their consequences, with particular reference to hygiene in the food industry. J. Appl. Bacteriol. 1993; 75: 499-511. http://dx.doi.org/10.1111/j.1365-2672.1993.tb01587.x

18. Gilbert P, Evans D, Evans E, Duguid I, Brown M. Surface characteristics and adhesion of Escherichia coli and Staphylococcus epidermidis. J. Appl. Bacteriol. 1991; 71: 7277. http://dx.doi.org/10.1111/j.1365-2672.1991.tb04665.x

19. Van Loosdrecht M, Lyklema J, Norde W, Schroa G, Zehnder A. Electrophoretic mobility and hydrophobicity as a measure to predict the initial steps of bacterial adhesion. Appl. Environ. Microbiol. 1987; 53: 1898-1901.

20. Dunne M. Bacterial adhesion: seen any good biofilms lately? Clin. Microbiol. Rev. 2002; 15: 155-166. http://dx.doi.org/10.1128/CMR.15.2.155-166.2002

21. Muñoz-Berbel X, Vigués N, Cortina-Puig M, Escudé R, García-Aljaro C, Mas J, Xavier Mu-oz F. Impedimetric approach for monitoring bacterial culture based on the changes in the magnitude of the interface capacitance. Anal. Methods. 2010; 2: 1036-1042. http://dx.doi.org/10.1039/c0ay00050g

22. Futschik K, PfutznerH. Electrode andmedia impedance for detection and characterization of microorganisms. Proceedings RC IEEE-EMBS \& 14th BMESI. 1995; 1.75-1.76. 
23. Liju Y, Chuanmin R, Yanbin L. Detection of viable Salmonella typhimurium by impedance measurement of electrode capacitance and medium resistance. Biosens. Bioelectron. 2003; 19: 495-502. http://dx.doi.org/10.1016/S0956-5663(03)00229-X

24. Manli G, Jinhua Ch, Xubin Y, Kun Ch, Lihua N, Shouzhuo Y. Monitoring of cell growth and assessment of cytotoxicity using electrochemical impedance spectroscopy. Biochim. Biophys. Acta. 2006; 1760: 432-439.

25. Bayoudha S, Othmaneb A, Ponsonnet L, Ouada HB. Electrical detection and characterization of bacterial adhesion using electrochemical impedance spectroscopy-based flow chamber. Coll. Surf. A. 2008; 318: 291-300.

http://dx.doi.org/10.1016/j.colsurfa.2008.01.005

26. Hondroulis E, Liu Ch, Li ChZ. Nanotechnology. 2010; 21: 315103doi:10.1088/0957-4484/21/31/315103. http://dx.doi.org/10.1088/0957-4484/21/31/315103

27. Kregiel D, Berlowska J, Szubzda B. Novel permittivity test for determination of yeast surface charge and flocculation abilities. J. Ind. Microbiol. Biotechnol. 2012; 39:1881-1886. http://dx.doi.org/10.1007/s10295-012-1193-y
28. Poortinga AT, Bos R, Norde W, Busscher H. Electric double layer interactions in bacterial adhesion to surfaces. Surf. Sci. Rep. 2002; 47: 1-32. http://dx.doi.org/10.1016/S0167-5729(02)00032-8

29. Van der Wal A, Norde W, Zehnder AJB, Lyklema J. Determination of the total charge in the cell walls of grampositive bacteria. Coll. Surf. B Bioin. 1997; 9: 81-100. http://dx.doi.org/10.1016/S0927-7765(96)01340-9

30. Valentinuzzi ME. Understanding the human machine, a primer for Bioengineering vol 4, 1st ed. New Jersey: World Scientific Publishing Company; 2004. http://dx.doi.org/10.1142/5597

31. Grosse C. Relaxation Mechanisms of Homogeneous Particles and Cells Suspended in Aqueous Electrolyte Solutions. In: Delgado A, editor. Interfacial Electrokinetics and Electrophoresis. New York: Marcel Dekker Inc.; 2002.P. 277327. 